\title{
Correction to: Building a low-cost domestic wastewater reclamation system using local agricultural waste in Kinmen islands, Taiwan
}

\author{
Hua-Yueh Liu' ${ }^{1}$ Shinne Chen ${ }^{2}$ \\ Published online: 29 November 2018 \\ (c) The International Society of Paddy and Water Environment Engineering and Springer Japan KK, part of Springer Nature 2018
}

\section{Correction to: Paddy Water Environ (2017) 15:809-819 https://doi.org/10.1007/s10333-017-0594-y}

In the original publication of the article, the affiliations of the authors have been mentioned incorrectly. Now the correct affiliations have been provided in this correction.

The original article can be found online at https://doi.org/10.1007/ s10333-017-0594-y.

Hua-Yueh Liu

lhyhmhs@nqu.edu.tw

1 Department of Architecture, National Quemoy University, 892 Kinmen, Taiwan, ROC

2 Consultant of Foundation Agricultural Engineering Research Center, Chung Yuan Christian University, Taoyuan,

Taiwan, ROC 